\title{
Comparative Study of Muslim Women's Education in the Context of employment, access to media, marital status, family planning and political participation - Case Study of Azamgarh District
}

\author{
Fauzia Islam ${ }^{*}$, Azimur Rahman, Naseema Khatoon, Vinay Kumar Pathak, \\ Mohammad Ali Imam \\ Department of Education Integral University, Dasauli, Kursi Road, Lucknow India
}

\begin{abstract}
This research is designed to explore the relationship between access to education of Muslim women and their access to media, marital status, family planning, and political participation status in Azamgarh district of Uttar Pradesh. The study used both qualitative and quantitative methods. The selection of the sample for the present study was made from the Muslim women of Azamgarh District of U.P., (India). The respondents were selected in random manner keeping in view the needs and objectives of the study. The representative sample is consists of 365 respondents. With respect to the former, in-depth interviews were used. This Study however shows that Education has had a positive impact on access to media and marital status of Muslim women in the district. However no influence of education was found on family planning and political participation of Muslim women in the district.
\end{abstract}

Keywords: Education, access to media, family planning, political participation

\section{Introduction}

Islam was the first religion which talked about rights of women. It legalized daughter's share in fathers' property, wives share in husband's income and duties of husband towards wives. For the first time a human treatment and legal status was given to women. Women were allowed to work, subject to certain condition. Thus compared to pre-Islamic position of women, Islamic legislation meant an enormous progress, the woman has the right to administer wealth she has brought into the family or has earned by her own work-[Schemmel (1992) page 65].It was the first time a human treatment and legal status was given to women. Women were also allowed to work, subject to certain condition. Thus compared to pre-Islamic position of women, Islamic legislation meant an all round progress for women where they had the right to work and earn and spend the earning in a way they thought best for it. ${ }^{1}$

Currently whatever studies on Muslim women are available are too diminutive and unbalanced in nature. Statistical micro studies on Muslim Women reiterate that the majority are among the most disadvantaged, economically impoverished and politically marginalized sections of Indian society today. These studies suggest that like other women, Muslim women too are not homogenous, and are differentiated along the vitiated lines of class, caste, community and religion. The plight of Muslim women in Indian context are similar to their counterpart of other religious vis-à-vis the evils of discrimination based on gender in spite of the fact that every year we observe "Women's day" and make loud and vocal claims of giving equality to women. This is because the social evils of the society at large have affected the Muslims so much so that they have lost sight of the basic principles of Islam on account of socio cultural intermingling. Their minority status does qualitatively transform women's experiences and perceptions in a very distinct way, and this transformation is central to understanding the development of women's subjectivity and consciousness. Social commentators have observed that the gendered politics of minorities have become more acute and complex in the last 15 years. ${ }^{2}$

Availability of employment opportunities provide an individual and her family with purchasing power, enabling her to acquire subsistence as well as consumption goods to satisfy the basic needs, comfort and leisure. In addition, enhanced earnings through employment allow investment. This can take the form of purchase of durable consumption goods and investments in areas like education, health and capital assets. Such investments are critical for increase in further incomes and for sustaining growth of the level of the individual as well as the economy. While economic benefits derived from such an increase in the entitlements are substantial, employment also has significant non-economic benefits. The belief that one is engaged in some worthwhile activity provides a sense of esteem and well being to the worker. ${ }^{3}$

Interestingly, work participation rates for Muslim women is much lower than even that for Women belonging to upper-caste Hindu households, where there may be socio-cultural constraints to women's work. Overall about 44 percent of women in the prime age group of 15-64 years in India participate in the workforce while about 85 percent of men do so. However, on an average the workforce participation rate among Muslim Women is only about 25 percent. In rural areas, while about 70 percent of the Hindu Women participate in the 
work force while only about 29 percent of the Muslim Women do so. Even the upper caste Hindu Women in rural areas has a higher participation rate which stands at 43 percent. The lower participation of Women in rural areas is partly explained by the fact that Muslim households are less likely to be engaged in agriculture. The worker population ratios (WPRs) for Muslim Women in Urban areas are even lower (18 percent), presumably because work opportunities for women within the household are very limited. Such opportunities may be somewhat higher in rural areas with ownership of land making participation of Muslim Women somewhat higher in this areas. ${ }^{4}$

One of the reasons for lower participation rates of Muslim Women may be higher dependency rates due to relatively higher share of younger population in the community, resulting in women staying at home. According to the Sachar committee report Muslim population is much younger than the total population. While 23 percent of the total population is below 10 years of age, 27 percent of Muslim population falls in this range. Further in the age group of 10-14 years, there is an excess of two percentage points for the Muslims. This is a situation of large young age dependency. However, the share of the elderly is not high both for the general population as well as the Muslim counterpart. Thus old age dependency is not high. Age specific work participation ratio shows that participation rates are lower for Muslims in almost all the age group for males and females, both in rural and urban areas. Therefore "young age dependency" does not seem to be driving to work participation ratio among Muslims.

Traditional barriers, in many cases, still prevent women from going out of their homes to work. This also limits the scope of work women can undertake and they often get into very exploitative subcontracting relationships. Moreover, women with responsibility for house hold duties (including children), find it difficult to work outside their homes or areas of residence.

There has been phenomenal progress on women's education since independence but still there is a wide gap between Muslim women's Education and other classes of Women education. Usually following causes of slow progress of Muslim women's education-

(i) Migration of upper and educated class of Muslims to Pakistan after partition of the country

(ii) Lack of a central leadership which is able to give voice to the actual needs of the community

(iii) Apathy of various governments and treating the community only as a vote bank

(iv) Lack of proper social attitudes in the rural and backward areas for the education of girls.

(v) Lack of educational facilities in Muslim's areas.

(vi) Economic backwardness of the Muslim Community.

(vii) Lack of suitable Curriculum.

(viii) Lack of proper incentives to parents and children.

(ix) Lack of women teachers.

(x) Lack of proper supervision and guidance due to inadequate women personnel in the Inspectorate.

(xi) Uneducated adult women and lack of social education.

\section{Conceptual Frame-Work}

Before embarking on any investigation or a sound footing it is customary to look into the existing literature on the chosen subject matter in order to have a feel of the intellectual directions and interpretations which may have informed the field of inquiry. It is mere prominent literature on what has now come to be known as women's studies.

By the middle of the sixties the so called counter cultural movement had gained momentum in Western Europe and North America. The younger generation on a collective level had begun to seriously question the traditional patterns of relationships so much dominated by considerations of age, sex, race, authority etc. Books and articles related to the status of Women in Western societies also began to appear more rapidly during that time.

Outstanding in the genre of literature are the works of Beauvoir (1960), Friedan (1963) and Finger (1972), which set the tone for what was to because a full fledged movement for women's liberation first at the intellectual and later at the political level. Millet's (1972) thesis followed by Cree's (1973) Exposition are note worthy precursors of a new aggressive feminist came in the literature on women's studies. Similar studies were not lacking in India either, although most of these were Journalists in character and did not warrant sociologically relevant conclusions. For instance Hales (1969) work on the status of women lacks the customary methodological rigor so essential sues purposes. Many others studies on Women's education, employment and social and legal rights are also available. Some of them even claim to be sociologically oriental efforts conducted by sociologically, studies by Baig (1957), Sengupta (1960), Mishra (1966), Kapur (1970), Warsi (1971), Sethi (1976), Carmarck (1961), Desai (1957), Mehta (1970) and Rani (1976) are noteworthy.

Women's empowerment is the process by which women gain control over material and intellectual resources and challenge the ideology of patriarchy and the gender based discrimination against women in al institutions and structure of society. 
I have discussed above in great detail the economic backwardness of Muslims due to various historical and socio-political reasons leading to a much poorer and vulnerable condition of Muslim women. In higher education Muslim women have an abysmal share at 3.56\%. Overall the Muslim girl child does face educational deprivation due to various reasons. The constitutional goal of eight years of schooling remains a dream with a Muslim girl getting 2-7 years of schooling compared to 3-8 of Hindu girls. About 59\% of Muslim girls in India never get into school and less than $10 \%$ complete it.

But Muslim girls are not uniformly poor and uneducated; they are much better off in south and also in the west.

Empowerment of women as described in National Policy of Empowerment of women 2002 takes Economic empowerment and social empowerment as its basic parameters. Economic empowerment includes poverty eradication and income generation and social empowerment includes education, health and nutrition etc. Apart from these parameters other aspects which determine women's empowerment are mobility, self esteem and choice of career. In the case of Muslim women the state of empowerment is still not clear hence a study about their actual status is required. In many cases we find a number of myths related to their rights being propagated by various extremist groups (both Hindu and Muslim).

The issues of women and Islam among masses have for quite some time attracted the interest of the intellectual and politicians. But much of this interest is caught up in misconception-Religion is seen to be the primary force influencing every aspect of their lives. They are still viewed as being out of the world where every move of their life is controlled by men and religious dogmas issued from time to time by various religious leaders and scholars. The spotlight is always on the role of religion in their life. It is normally believed that they are strictly controlled by Muslim personal law ${ }^{6}$.

The objective of this study is to study the Muslim women as common human beings, their problemslike poverty, non-accessibility to recourses etc. and how far after being educated they are able to overcome it.

It is by and large observed that while the outsiders carry a very biased view of Muslim women and are generally not aware of the reality, Muslim women also tend to not realize their actual status.

Most of them are not clear about the rights given to them by Islam as a religion as well as the Indian constitution. This study aims at bringing about general awareness among the Muslim women about their status, rights and duties.

The social status of Muslim women as projected in the outside world is the result of select cases of Muslim women passionately discussed in media. It has resulted in identifying the Muslim religion as a sole locus of gender in justice in the country.

According to the Sachar Committee report as a result of such biased propaganda the civil society and the state locate Muslim women's deprivation not in terms of the 'objective' reality of societal discrimination and faulty development policies, but in the religious community space.

Furthermore when the community identity is under siege it affects women in a dramatic ways. Women sometimes out of their will, sometimes under community pressure adopt visible markers of community identity on their person and in their behaviour. Such behaviour generally hampers the serial, educational and economic growth of M.W.

This study tries to bring out the problems being faced by Muslim women serially and its impact on their development.

The morality of women and movement in public spaces are under constant scrutiny and control. A gender based fear of the 'public' experienced to some degree by all women, is magnified manifold in the case of Muslim women. A rigid line is drawn between safe and unsafe places. The community and its women seem to withdraw into the safety of familiar orthodoxies, reluctant to participate in the project of modernity. Many of the community feel that the only 'safe' place for women is within the boundaries of home and community.

This hampers the development of women and reduces their opportunities. This study aims at studying the social status of Muslim women and suggests ways for their social enlistment.

Muslims in general have a poor representation in employment market. This number is poorly represented in public employment. Displacement from traditional occupation has contributed to Muslims being deprived of their means of livelihood and has led to economic backwardness. Muslims by large are engaged in the unorganized sector of the economy which rarely enjoys protection of any kind.

Muslims are overwhelmingly self employed (engaged in home based work). Sewing, embroidery, Zari work, chikan work, readymade garments, agarbatti and beedi rolling are some of the occupations in which Muslim women are concentrated. Their work conditions are characterized by low income, poor work conditions.

The distinct pattern of Muslim women's employment in home -based work is in part due to discrimination in formal employment. In part it is due to vicious cycle of poverty, lack of education and technical skills etc. Muslim women are unable to bargain for better work conditions because much of work they do is subcontracted. This restriction of mobility restricts their employment opportunities and wages. Many home 
based workers are so low down in the assembly line of production that they operate entirely through middlemen and do not even know who their employer is.

This study aims at studying this condition and trying to improve their economic condition so that they have better economic opportunities.

Every research study deals with solution of some problems of human interest. That is why the researcher has a definite purpose he/she has certain specific aims to achieve through his/her research wok. Such specific goals or purposes of research are technically termed as objectives. Every research work must have some objectives to achieve without which no research can be conducted. The entire research process is guided by objectives, which have been explicitly and presently spelled out by the investigator in advance. The basic objective behind selecting this particular topic can be enumerated as below:

1. To study the relationship between education and socio-economic status.

2. To study the relationship between education and employment.

3. To study the relationship between education and access to media.

4. To study the relationship between education and marital status.

5. To study the relationship between education and family planning.

6. To study the relationship between education and political participation.

\section{Methods And Materials/Tools}

The method adopted for the present study was descriptive and statistical in nature. Such studies are designed to obtain pertinent and precise information concerning the current status of phenomena and, whenever possible, to draw valid general conclusions from the facts discovered. They are restricted not only to fact finding but may often result in the formulation of important principles of knowledge and solution of significant problems concerning local, state, national, and international issues. Descriptive studies are more than just a collection of data. They involve measurement, classification, analysis, comparison and interpretation.

Tools Used:-

Nature of the questions households for the study of Education and Socio-Eco- Empowerment of Muslim Women were basically related to the.

- General Information

- Education

- Access to Media

- Marriage

- Employment

- Mobility and Decision Making

- Political participation.

\section{Comparative Analyses:-}

- To define Education and Socio-Economic-Empowerment of Muslim Women we compare the position of Muslim Women of Azamgarh district to the other women of village and town population of this district. We analyzed the present condition of Muslims Women in a comparative perspective. For this purpose we used the comparative analysis as different sources of data provide different types of information.

- As the objective was to assess the status of Muslim Women, the sample selected was purposive and based towards the Muslim population of Azamgarh district. According to the 2001 census district's population, of which 77.8 percent live in rural areas and 22.2 percent in urban areas. A larger number of Muslims, than members of other religions, live in urban areas. The difference in the universe and the sample is, therefore, the result of a purposeful decision to focus greater attention on the Urban population, with the sample allocated to Urban and rural areas in the ratio of 60:40. A part from this basic difference, other background information, such as age, gender, religion, education, main occupation and community groups point to the wide coverage and representative ness of the sample.

- As far as possible, we have been able to get data of only Muslims Women without the break up between Muslim OBC's Women and Muslims Women of the General Category.

\section{Results And Analysis}

The objectives of the present study were to empirically test the assumptions regarding relationship between Muslim women education and other factors (SES, Employment, Marital Status, Family Planning, and Access to Media, Mobility, Rights \& Duties, Decision Making, and Self Esteem). In order to test the hypotheses percentage and correlation were employed to study the difference between the means of Muslim Women education and other factors. 
Comparative Study of Muslim Women's Education in the Context of employment, access to media,

\section{a) Impact of Access to Media on Education}

Here we focus on access to the media television, radio and newspaper. In low literacy families and societies, not-print mass media as radio and television are a more important source of entertainment and information than the print media epically for women. To accesses access their exposure to media we asked a number of questions on the print and electronic media.

Table 1: Mean Score $( \pm$ SD) of All the variables

\begin{tabular}{|l|c|c|c|}
\hline & Mean & Std. Deviation & N \\
\hline Education & 4.49 & 1.261 & 365 \\
\hline Access of Media & 7.42 & 4.310 & 365 \\
\hline Political Participation & 6.16 & 3.668 & 365 \\
\hline Employment & 3.98 & 4.650 & 365 \\
\hline Marital Status & 1.72 & 1.222 & 365 \\
\hline Family Planning & .50 & 1.106 & 365 \\
\hline Voluntary Services & .35 & .755 & 365 \\
\hline Mobility & 2.41 & 1.562 & 365 \\
\hline Self Esteem & 5.33 & 3.375 & 365 \\
\hline Rights \& Duties & 3.49 & 2.001 & 365 \\
\hline
\end{tabular}

Figure 1: Graphical representation of Mean Scores of all variables

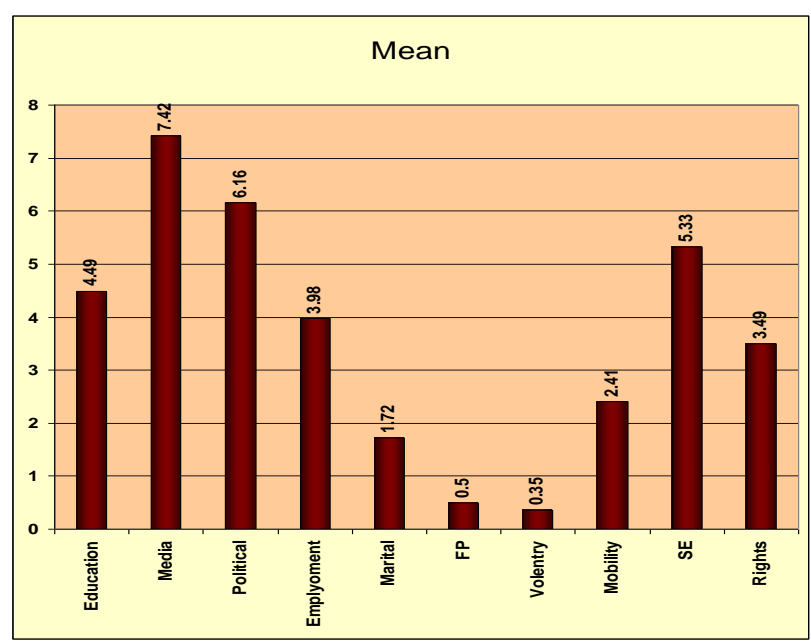

Table 2: Pearson's Correlation among different variables

\begin{tabular}{|c|c|c|c|c|c|c|c|c|c|c|}
\hline & 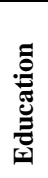 & 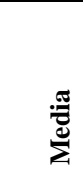 & 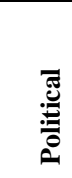 & 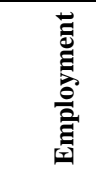 & & 空 & 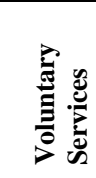 & $\begin{array}{l}\frac{3}{7} \\
\frac{0}{2}\end{array}$ & 颁 & 莺 \\
\hline Education & 1 & $.213 * *$ & .052 & $.118^{*}$ & $.141^{* * *}$ & -.059 & $.137 * *$ & $.193 * *$ & $.244 * *$ & $.203 * *$ \\
\hline Media & & 1 & .027 & $.204 * *$ & $.175^{* * *}$ & -.026 & .059 & .101 & $.272 * *$ & $.242 * *$ \\
\hline Political & & & 1 & .086 & $.138^{* * *}$ & -.021 & .074 & .076 & $.195 * *$ & $.156^{* * *}$ \\
\hline Employment & & & & 1 & .087 & .091 & .089 & .008 & .065 & $.191^{* *}$ \\
\hline Marital & & & & & 1 & $.112^{*}$ & -.033 & $.146 * *$ & $.263 * *$ & $.183^{* * *}$ \\
\hline FP & & & & & & 1 & .022 & .073 & .060 & .062 \\
\hline Voluntary S. & & & & & & & 1 & .069 & .102 & $.144 * *$ \\
\hline Mobility & & & & & & & & 1 & $.355^{* * *}$ & $.200 * *$ \\
\hline SE & & & & & & & & & 1 & $.426 * *$ \\
\hline Rights & & & & & & & & & & 1 \\
\hline
\end{tabular}

When we analyze on total basis we found that 160 respondents are those who access media on regular basis, 197 respondents are those who access media on sometimes basis and 8 respondents are those who never access the media. On the whole 43.84 percent respondents' use media regularly, 53.97 percent respondents use 
media sometimes and 2.19 percent respondents never access the media. The percentage was applied for investigation, the detailed percentage values are given in table 3 .

b) Regular Access to Media:

Out of 365,160 respondents access to the media on regular basis in which 5 respondents are illiterate, 6 respondents are primary, 25 respondents are middle, 46 respondents are intermediate, 41 respondents are graduate and 37 respondents are post- graduate or above in education.

On the whole 3.13 percent respondents are illiterate, 3.75 percent respondents are primary, 15.63 percent respondents are illiterate middle, 28.75 percent respondents are intermediate, 25.63 percent respondents are graduates and 23.13 percent respondents are post graduate.

c) Sometimes Access to Media:

Out of 365, 197 respondents access to the media on sometimes basis in which 6 respondents are illiterate, 6 respondents are primary, 28 respondents are middle, 37 respondents are intermediate, 71 respondents are graduate and 49 respondents are post- graduate or above in education.

On the whole 3.05 percent respondents are illiterate, 3.05 percent respondents are primary, 14.21 percent respondents are illiterate middle, 18.78 percent respondents are intermediate, 36.04 percent respondents are graduates and 24.87 percent respondents are post graduate.

Figure 2: Graphical representation of Correlation among the variables

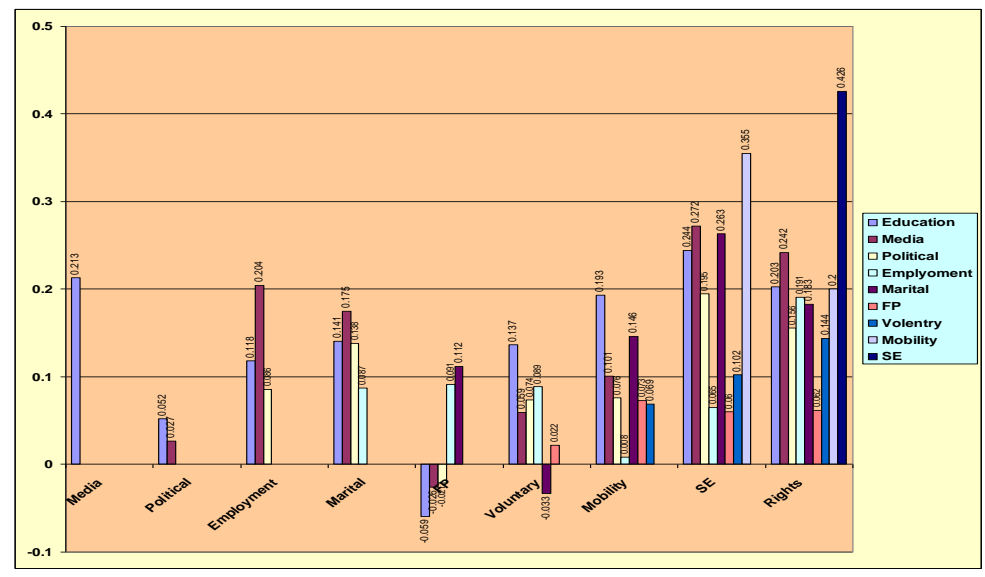

\section{d) Never Access to Media:}

Out of 365,8 respondents access to the media on regular basis in which 1 respondent is middle, 2 respondents are intermediate, 3 respondents are graduate and 2 respondents are post- graduate or above in education.

On the whole 0.00 percent respondents are illiterate, 0.00 percent respondents are primary, 12.50 percent respondents are illiterate middle, 25.00 percent respondents are intermediate, 37.50 percent respondents are graduate, and 25.00 percent respondents are post graduate.

Table 3: Comparison of percentage of education on the basis of their access to media

\begin{tabular}{|c|c|c|c|c|c|}
\hline \multicolumn{2}{|c|}{ REGULAR ACCESS TO MEDIA } & \multicolumn{3}{c|}{ SOMETIMES ACCESS TO MEDIA } \\
\hline EDUCATION & FREQUENCY & $\%$ & EDUCATION & FREQUENCY & \% \\
\hline 1 & 5 & 3.13 & 1 & 6 & 6 \\
\hline 2 & 6 & 3.75 & 2 & 28 & 3.05 \\
\hline 3 & 25 & 15.63 & 3 & 37 & 14.21 \\
\hline 4 & 46 & 28.75 & 4 & 71 & 3.78 \\
\hline 5 & 41 & 25.63 & 5 & 49 & 24.87 \\
\hline 6 & 37 & 23.13 & 6 & 197 & 100.00 \\
\hline
\end{tabular}

\begin{tabular}{|c|c|c|c|c|c|}
\hline \multicolumn{3}{|c|}{ NEVER ACCESS TO MEDIA } & \multicolumn{3}{|c|}{ TOTAL DATA } \\
\hline EDUCATION & FREQUENCY & $\%$ & ACCESS TO MEDIA & FREQUENCY & $\%$ \\
\hline 1 & 0 & 0.00 & REGULAR & 160 & 43.84 \\
\hline 2 & 0 & 0.00 & SOMETIMES & 197 & 53.97 \\
\hline 3 & 1 & 12.50 & NEVER & 8 & 2.19 \\
\hline 4 & 2 & 25.00 & & 365 & 100.00 \\
\hline 5 & 3 & 37.50 & & & \\
\hline 6 & 2 & 25.00 & & & \\
\hline & 8 & 100.00 & & & \\
\hline
\end{tabular}

Table 4: Comparison of mean scores of access to media on the basis of education 
Comparative Study of Muslim Women's Education in the Context of employment, access to media,

\begin{tabular}{|c|c|c|c|c|c|}
\hline Variables & $\mathbf{N}$ & Mean & Std. Deviation & Correlation & Significance \\
\hline Education & 365 & 4.49 & 1.261 & \multirow{2}{*}{ At 0.01 level } \\
\hline Access to Media & 365 & 7.42 & 4.310 & 0.213 & \\
\hline
\end{tabular}

The analysis was employed to find out the influence of access of media on education. The total samples were 365. The mean scores of access of media and education of respondents were found to be 7.42 and 4.49 respectively. The correlation was applied for investigation, the mean scores, SD and $\mathrm{r}$ values are given in table 4. The analysis does not confirm the prediction hypothesized in this study for the present sample. A relationship between student's education and access to media has been demonstrated by this finding. Hence, the third hypothesis stating that, there is no significant difference between education and access to media was rejected at 0.01 level of confidence. The graphical presentation of percentage scores of Education and Access to Media is given in fig. 3 .

\section{(i) Relationship between Education and Marital Status}

Marriage in India is universal. It is found in all religions and categories. The overwhelming majority of women across all social groups are currently married, with the next biggest categories being widowed and never-married; at the all - India level, these are the three most significant categories.

The analysis was employed to find out the influence of education on marital status. The total samples were 365. The mean scores of education and marital status of respondents were found to be 4.49 and 1.72 respectively. The correlation was applied for investigation, the mean scores, SD and $\mathrm{r}$ values are given in table5. The analysis does not confirm the prediction hypothesized in this study for the present sample. A relationship between student's education and marital status has been demonstrated by this finding. Hence, the fourth hypothesis stating that, there is no significant difference between education and marital status was rejected at 0.01 level of confidence. The graphical presentation of mean scores of Education and Marital status is given in fig. 4.

Figure 3: Graphical presentation of Access to Media on Education Basis

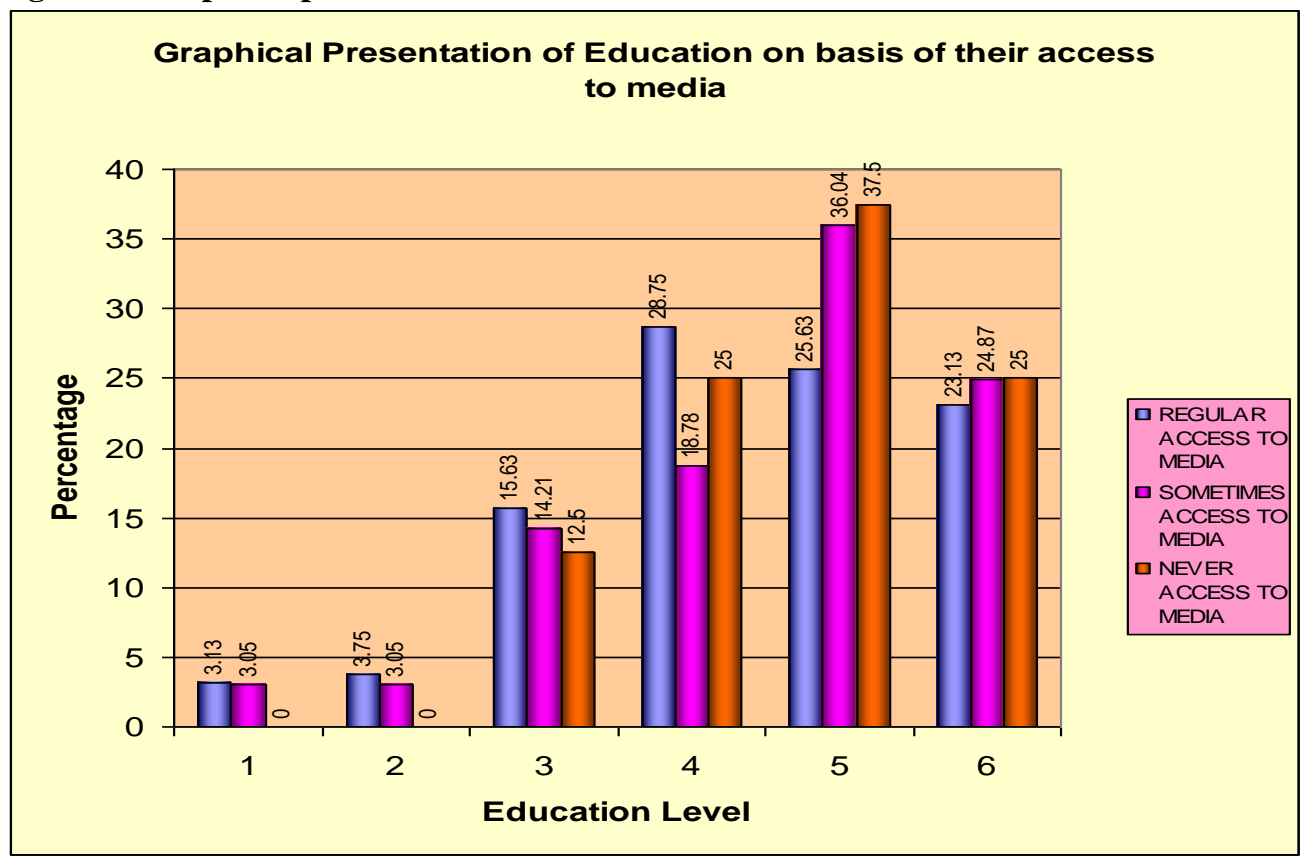

Table 5 Comparison of mean scores of marital status on the basis of education

\begin{tabular}{|c|c|c|c|c|c|}
\hline Variables & $\mathbf{N}$ & Mean & Std. Deviation & Correlation & Significance \\
\hline Education & 365 & 4.49 & 1.261 & & \\
\cline { 1 - 3 } Marital status & 365 & 1.72 & 1.222 & \multirow{2}{*}{0.141} & At 0.01 level \\
\hline
\end{tabular}

Figure 4: Graphical presentation of Marital Status on Education Basis 


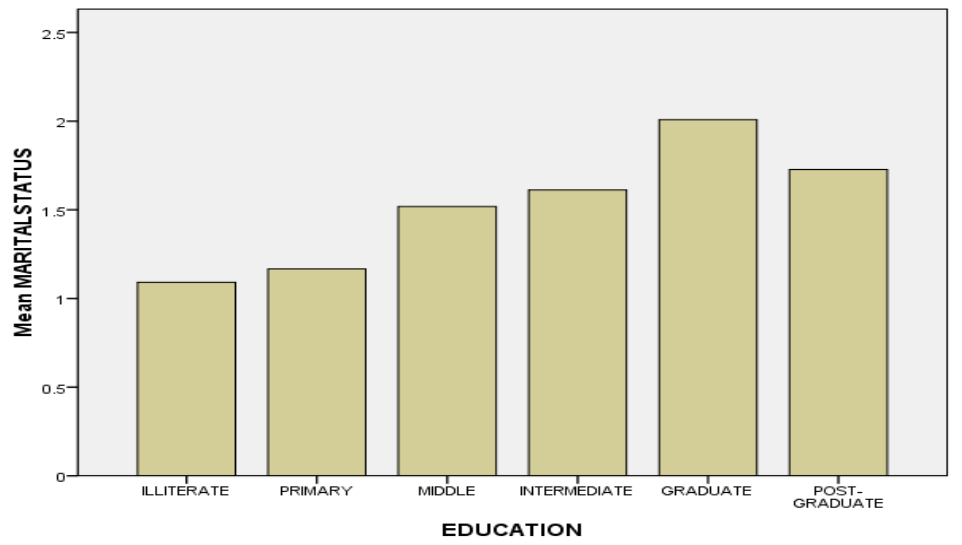

(ii) Relationship between Education and Family Planning

Most of the respondent said that they followed the norms of legal minimum age at marriage. For this attitudes we can concluded that an unambiguous gender bias is evident in these attitudes, with an implicit and explicit recognition that house holding and breadwinning are male responsibilities and reproduction, domestic activities and caring for the family are women's Jobs, for which physical maturity is necessary. Thus in our sample we found that majority of respondents wanted later (above 18 years) marriage for girls. This becomes also clearer when we note that, for those women who expressed a preference for marriage at 18 years or later, an important reason is being able to get a better education.

The analysis was employed to find out the influence of education on family planning. The total samples were 365. The mean scores of education and family planning of respondents were found to be 4.49 and 0.50 respectively. The correlation was applied for investigation, the mean scores, SD and ' $r$ ' values are given in table 6 . The result clearly indicates that there is no significant difference between mean score of education and family planning. Thus the fifth hypothesis of the study that "there is no significant difference between education and family planning." is accepted. The graphical presentation of mean scores of Education and family planning is given in fig. 5.

Table 6 Comparison of mean scores of family planning on the basis of education

\begin{tabular}{|c|c|c|c|c|c|}
\hline Variables & $\mathbf{N}$ & Mean & Std. Deviation & Correlation & Significance \\
\hline Education & 365 & 4.49 & 1.261 & \multirow{2}{*}{-0.059} & \multirow{2}{*}{ Not Sig. } \\
\hline Family Planning & 365 & 0.50 & 1.106 & -0.05 & \\
\hline
\end{tabular}

Figure 5: Graphical presentation of Family Planning on Education Basis

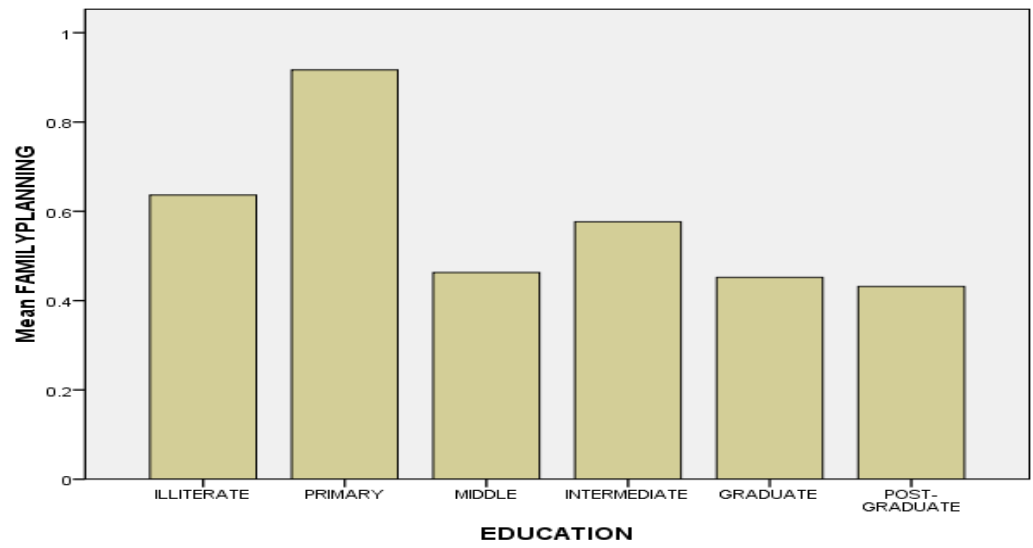

(iii) Relationship between Education and Political Participation

The situation of Muslim Women in independent India has attracted a good deal of attention from scholars, activists and policy makers. However much of this attention has been focused on the educational legal and socio-economic disadvantage faced by Muslim Women with little interest being shown in their involvement in the political sphere.

In scenario we summarizes the historical background to the participation of Muslim Women in politics, as well as the changes wrought to Muslim's women status in independent India. In this scenario we will analyze 
the issue of the percent of Muslim women in both national and provincial politics. Women's participation in elections and politician activities is an important means by which women gain status and autonomy, but their presence in party politics and leadership remains limited. Their low political representation, however, does not appear to have any correlation to their voter turnout or political awareness. Women are quite conscious of the importance of their vote and regularly exercise their franchise. Here we seek to understand and assess the nature of women's political participation. To assess women's involvement in political activities, we asked a number of questions regarding their participation during elections and their willingness contest in elections. Respondents were asked about the age of voting. We asked them; at what age does a person acquire the right to vote?

The analysis was employed to find out the influence of education on political participation. The total samples were 365 . The mean scores of education and political participation of respondents were found to be 4.49 and 6.16 respectively. The correlation was applied for investigation. The result clearly indicates that there is no significant difference between mean score of education and political participation. Thus the seventh hypothesis of the study that "there is no significant difference between education and political participation" is accepted. The graphical presentation of mean scores of Education and political participation is given in fig.6.

\section{Figure 6: Graphical presentation of Political Participation on Education Basis}

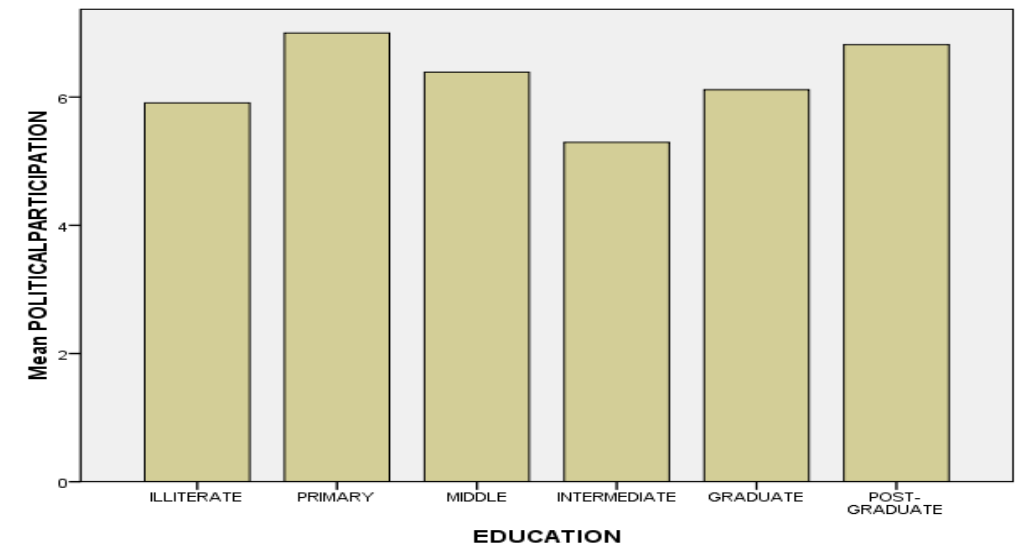

\section{DISCUSSION}

The purpose of the present research was to determine the effect of education on empowerment of Muslim women in Azamgarh district. This variable was chosen for analysis because this is a manipulatable variable that has been identified as important influence of education in previous researches. Data from a large contemporary sample of respondents from district were analyzed. Correlation was used to determine the effects of this variable on education.

The results of the analysis of data show that the political participation and family planning had no significant effect on empowerment of Muslim women in Azamgarh district.

There is significant difference between education and access to media. The finding of this study is supported from earlier trend that with increase in educational qualification the interest in media also increases directly.

There is significant difference between education and marital status. The finding of this study that there is significant difference between education and marital status is supported by Choudhary P.K. (1988), Mahesh, R. (1991), Zoya Hasan \& Ritu Menon; Basu, Alaka (1997) and Rajvanshi, J. (1991) found that higher education of girls resulted in late marriages, and employed girls seemed more selective in the choice of their marital partners working. Women enjoyed a better status compared to non-working women but also reported greater role-conflict.

There is no significant difference between education and family planning. The finding of this study is supported by Kantamma, K. (1990), but Choudhary P.K. (1988), Fatima, N.J. (1989), and Devi, T. V. (1991) found a positive relationship between the educational and socio-Economic background of women and adoption of family planning methods.

There is no significant difference between education and political participation. The finding of this study is supported by Krewer (1992), Mari Bhat, P.N (2002 a, 2002b) and Mahesh, R. (1991) reveals that the level of political participation is very low among rural women, irrespective of marital status, religion, castes and occupation. The political participation of women in higher in nuclear families the educational level of rural women, higher their political 
participation. Around $89 \%$ respondents have a lower level of obligatory and spectacular political participation.

\section{CONCLUSION}

The Indian constitution is committed to the equality of citizens and the responsibility of the state to preserve, protect and assure the right of minorities in matters of language, religion and culture. That is why our national leaders while farming the constitution, emphasized the doctrine of unity in diversity. All developed countries and most developing ones give appropriate emphasis to looking after the interest of minorities. In any country, the faith and confidence of the minorities in the function of the state in an impartial manner is an acid test of its being a Just state. As the processes are likely to build up and intensify where there is unequal development and some groups or minorities lag behind in the development process. Ideally, development processes should remove or reduce economic and social obstacles to cooperation and mutual respect among all groups in the country.

With all the variations in Women's education across this district, one indisputable fact emerges from analysis that there are large and systemic differences between groups in terms of educational attainment. The data confirm the disadvantaged educational status of Muslim Women. The general picture emerging is one of modest educational achievement, marked by an appallingly high level of illiteracy and enormous inequalities in schooling between different groups. In our analysis we found that 16.89 percent respondents had never attended school which is a high proportion indeed. Their presence in higher education in minuscule, even lower than that for scheduled caste women. Among the literate, Hindu Women were better educated than Muslims, and among Hindus, upper castes were better educated. Respondents from households with a higher socio-economic status were more educated than those from poor households. Both Hindus and Muslims favors significantly more higher education for boys than for girls. Enrolling girls in school in only half the battle, because it is meaningful only if they complete the minimum of eight years of schooling which requires that their families be able to resist the pressure of income generation and work in the home. Generally, Muslims lag behind in educational attainment, their prospects of going beyond primary rather lower than that of Hindus and completing school even lower for Muslim Women, not being able to enter the schooling systems to be the first obstacle. "Those that do manage entry do not seem to be able to continue schooling, let alone go on to higher education. Education is an essential means for participation in the economy and society, it can mitigate the impact of social inequality; empirical studies have in fact shown higher returns to education for Muslim Women than men, but only education beyond the Junior/middle level enhances economic activity and participation."12

For economically disadvantaged groups such as Muslims, education would be the most promising means of upward mobility. However the prospects of girls from poor families continuing in schools is quite small in comparison to non-poor families who are almost certain to enter school with a good prospect of reaching middle and even higher secondary levels.

The study was limited to Azamgarh District.

\section{Delimitations}

Only women population of age group 15 years and above was studied.

Only Muslim women population was studied.

Empowerment (of women) was studied with regard to following dimensions only:

$>$ Decision making

$>$ Employment

$>$ Economic Status

$>$ Self Esteem

$>$ Mobility / Social Mobility

$>$ Knowledge of Rights / Duties

\section{REFERENCES}

[1]. Zoya Hasan and Ritu Menon- Unequal citizens, Oxford University Press. New Delhi, 2004, pp. 3.

[2]. Zoya Hasan and Ritu Menon- In a Minority, Oxford University Press, New Delhi, 2005.

[3]. Sachar Committee Report, Page- 87. Sacchar Committe Report Nov 2006)I " Social, economic and educational status of the Muslim community of India- a report", Prime minister's High level Committee, Government of India, November 2006. Page- 87

[4]. Sachar Committee Report, Page- 89-90

[5]. Zoya Hasan \& Ritu Menon- Unequal Citizens

[6]. D. Malathy and P. Duraiswamy; 'Returns to scientific and Technical Education in India; Margin, 21 (5), September 1998.

[7]. Kantamma, 1990 status of Women in relation to education, employment and marriate. M. Phil. Adult Education. Sri Vinkateshwara University.

[8]. Fatima, Nusharat Jahan 1989 Education, serial mobility and serial change among women in Banglore city. Ph.D. Education University of Mysore.

[9]. Chaudhary, Pritima K. (1988) changing values among young women Ph.D, Soc, A.N. Sinha Institute of social studies, Patna. 
Comparative Study of Muslim Women's Education in the Context of employment, access to media,

[10]. Mari Bhat, P. N. 2002a Demographic Transition, Family Size and child schooling, working paper series No 87, National council of Applied Economic Research, New Delhi.

[11]. Rajvanshi, Jyotsna (1991). Education status mobility and social change: A comparative sociological study of educated middle class working women Ph.D. Sociology University of Rajasthan.

[12]. D. Malathy and P. Duraiswamy; 'Returns to scientific and Technical Education in India; Margin, 21 (5), September 1998. 